\title{
In pursuit of food system integrity: the situational prevention of food fraud enterprise
}

\author{
Nicholas Lord ${ }^{1}$ (D) Jon Spencer ${ }^{1} \cdot$ Jay Albanese $^{2}$. \\ Cecilia Flores Elizondo ${ }^{1}$
}

(C) The Author(s) 2017. This article is an open access publication

\begin{abstract}
There is much talk surrounding food fraud policy, and while there is convergence around the need to 'do something about it', there can be divergence around how this should be done as seen in the decisions and actions of concerned stakeholders. However, underpinning the policy agendas in relation to food fraud there is an aim to prevent (or at least reduce) food fraud, crime and harms, to improve the integrity of the food system. This article develops a mode of analysis that integrates 'enterprise theory' with 'situational prevention theory' to develop an understanding of how food frauds are situated actions, shaped by contingent enterprise conditions that influence how food frauds are organised and why decisions to offend become rational. We apply this integrated framework to the Spanish olive oil market. Drawing on data collected on market conditions and case study analyses of particular frauds to better understand the situated nature of food frauds we suggest mechanisms that could be used to prevent fraud in particular situations under these conditions. We conclude that this mode of thinking and analysis can be applied to a range of frauds across different food networks.
\end{abstract}

Keywords Food fraud $\cdot$ Food crime $\cdot$ Enterprise theory $\cdot$ Situational prevention $\cdot$ Food integrity

\section{Introduction}

There is considerable talk surrounding food fraud policy with a convergence around the need to 'do something about it' and a divergence around how this should be done as seen in the decisions and actions of concerned stakeholders. Food fraud is associated with varying policy responses - 'food safety', 'food crime', 'food standards', 'food integrity', 'food authenticity', 'food security', 'food defence' — each imply different forms of regulatory action. These range

Nicholas Lord

nicholas.lord@manchester.ac.uk

1 Centre for Criminology and Criminal Justice, University of Manchester, Manchester, UK

2 Virginia Commonwealth University, Richmond, VA, USA 
from regulatory measures to persuade business to comply with prescriptive standards including self-regulation through the criminal sanctioning of individual offenders to the development of DNA testing of food products, each having a place within a broader regulatory framework.

Underpinning each of these policy agendas is a need to prevent food fraud, food crime and food harms, and to improve the integrity of the food system. This was central to the Elliot Review into the integrity and assurance of food supply networks (Elliot 2014). We argue in favour of a mode of analysis that foregrounds food fraud as 'situated action' and pursues proactive and preventive 'before the fact' policies and interventions, rather than more repressive and reactive 'after the fact' responses. ${ }^{1}$ As Spink and Moyer (2011:R159) note, '[w]hile classic intervention and response tactics have value whenever public health is threatened, proactive prevention is the logical progression' and this requires recognition that 'the root cause of food fraud has fundamentally different properties' to other policy agendas such as food safety. This is particularly necessary where food frauds are better understood as 'endogenous' practices by legitimate market actors and culturally embedded within the food system, rather than being exceptional events perpetrated by supply chain 'outsiders' (Lord et al. 2017a). To do this, the article presents a conceptual and analytical framework for understanding food frauds as situated actions, shaped by contingent enterprise conditions, and developing associated situational mechanisms to prevent and reduce these undesired, 'entrepreneurial' behaviours at the level of necessity.

This article begins with a brief overview of how we can conceptualise 'food fraud'. We then outline a theoretical model that incorporates enterprise theory with situational prevention theory. This demonstrates how we understand food fraud activities as choices and actions shaped by contextual and structural factors and conditions. Dominant food fraud narratives focus on identifying and catching the offending individuals and groups, or on the fraudulent products. For the purposes of prevention and reduction more can be gained from concentrating on the situations where fraudulent activities occur. To demonstrate the utility of this approach, we apply this analytical framework to the case of olive oil adulteration, drawing on our research into the Spanish olive oil market that included interviews with market actors and an analysis of three cases of olive oil fraud. This case study is one of a range of cases analysed as part of an ESRC/Food Standards Agency (FSA) funded project that aims to understand the challenges of the food system. It is our contention that this mode of analysis provides a fuller theoretical account of food fraud by understanding the dynamics between individual actions, situational environments and wider structural drivers and pressures. Such an analysis can be applied to a range of frauds across different food networks and can underpin food system integrity.

\section{What is 'food fraud'? Concepts and integrity: a brief overview}

At its most basic level, the concept of fraud, as it is commonly understood, is 'a way of making money illegally via deception' (Levi 2012: 7) that involves a process of some form of dishonest or deceptive practice and an outcome that is some form of advantage as a 'goal'. It has also been called 'larceny by trick,' given its fundamental aim to obtain property by deception (Albanese 1995: 34). Food fraud is one form of the broader concept of food crime

\footnotetext{
${ }^{1}$ The argument here is not that repressive, punitive measures have no place in the regulatory framework, but that prevention offers a more viable approach to reducing fraud.
} 
and despite being a longstanding phenomenon (Shears 2010), has recently emerged as a priority policy focus domestically and internationally (Lord et al. 2017a). Supranational organisations, such as the EU, are becoming progressively concerned that recent cases signal an increase in the number of food fraud incidents and that this trend reflects a structural weakness within the food chain (European Parliament 2013: 5). While there are no valid indicators of, or data on, the extent and scope of food frauds locally or transnationally to verify any such increases or trends, actual (and potential) health and fiscal harms have been evidenced in discrete cases in the UK. ${ }^{2}$ Food fraud incidents undermine trust and confidence in individual businesses of varying size, ${ }^{3}$ and in particular product markets more generally, as consumers alter their consumption behaviours. Manning (2016) argues that fraud in the supply chain can emerge because of misrepresentation associated with the 'integrity' of food products (i.e. quality/authenticity), processes (i.e. activities inherent in production), people (i.e. honesty/ morality of actors) and data (i.e. consistency and accuracy of accompanying information). Pursuing a high level of food system integrity across these variables is both necessary and desirable for regulators, businesses and consumers given these varied harms.

The term food fraud has been variously defined and conceptualised but predominantly in terms of 'content' by outlining specific offences or types of fraud. Spink and Moyer (2011) delineate different types of food fraud: adulteration, tampering, over-run, theft, diversion, simulation and counterfeit. Similarly, Bouzembrak and Marvin's (2016) analysis of notifications data collated through the EU's Rapid Alert System for Food and Feed (RASFF) in the period 2000-2013 established six different fraud types: (i) improper, fraudulent, missing or absent health certificates, (ii) illegal importation, (iii) tampering, (iv) improper, expired, fraudulent or missing common entry documents or import declarations, (v) expiration date and (vi) mislabelling. This approach is closely aligned with policy discourse as seen in a 2014 Activity Report ${ }^{4}$ from the EU's Food Fraud Network, established following the horsemeat scandal in 2013, which indicated that of those cases that came to their attention, most violations related to 'labelling non-compliance', 'falsified certification/documents', and 'substitution'; meat foodstuffs were the subject of the most cases, followed by fish and honey. The $2015^{5}$ iteration of the report again identified 'labelling non-compliance' but also 'suspicion of illegal exports' and 'prohibited treatments and/or processes' as the most frequent violation types.

Defining food fraud in terms of known violations, notifications and offences is undoubtedly useful for policy discourse, but an appreciation of how these definitions are more an artefact of the data and method is often lacking. For instance, state authorities define their focus in terms of the cases that come to their attention but this may be a reflection of enforcement activity rather than the inherent nature of the actual behaviours. Instead, analytical definitions are more suited to developing an understanding of the relations and behaviours that constitute the actual frauds. More analytically then, we can argue that food fraud relates to:

'...the abuse or misuse of an otherwise legitimate business transaction and an otherwise legitimate social/economic relationship in the food system in which one or more actors

\footnotetext{
${ }^{2}$ For example, Paul Wilson died in January 2014 following an allergic reaction to a curry containing peanuts while Tesco lost $£ 300 \mathrm{~m}$ off its market value following the horsemeat scandal (though we might question their culpability alongside their 'victim' status).

${ }^{3}$ Business harms are most likely to be disproportionately damaging for small and medium sized companies as larger corporations are able to absorb the reputational damage over time.

${ }^{4} \mathrm{http}$ //ec.europa.eu/food/safety/docs/official-controls_food-fraud_network-activity-report_2014.pdf

${ }^{5} \mathrm{http} / / /$ ec.europa.eu/food/safety/docs/official-controls_food-fraud_network-activity-report_2015.pdf
} 
undertakes acts or omissions of deception or dishonesty to avoid legally prescribed procedures (process) with the intent to gain personal or organisational advantage or cause loss/harm (outcome)' (Lord et al. 2017a).

Fraudulent activities, involving small or large scale criminal enterprise, undermine the integrity of local and global food systems. Consumer confidence and trust are damaged as there is the perceived loss of the 'right' to be provided with unadulterated and authentic products. Responding to such food fraud risks and criminal enterprise is emerging as a primary public policy concern (see National Food Crime Unit 2016).

\section{Theoretical framing: Integrating 'enterprise' and 'situational' theory}

In this article food fraud is framed as a commercial 'enterprise' crime (see Naylor 2003: 88). That is, food fraud inheres illegal, fraudulent behaviours that are dishonestly concealed within and behind lawful market acts and processes by legitimate occupational actors for some form of profit or advantage in the food system. By 'enterprise', we mean the modes of thinking and behaving that correspond with the pursuit of wealth generation through economic activities embedded within business and markets of exchange and the conditions that shape these. ${ }^{6}$ Associated entrepreneurial behaviours involve the production, distribution and exchange of fraudulent food products disguised as licit products within a legal, commercial marketplace and involve behaviours, relations and acts (or omissions), such as adulteration and mislabelling, that are socially organised around commercial opportunities. Thus, as Smith (1980: 358-386) argues, some forms of organised criminal behaviour actually operate like legitimate businesses with the underlying assumptions that govern entrepreneurship in legitimate marketplaces also being evident in criminal enterprise. These actors behave much like purely legitimate actors, where we see a desire to maintain and extend market share in the pursuit of economic gain.

If actors at both sides of the product exchange were aware of the illegal production, then we might say the market is illegal (see Beckert and Wehinger 2013: 9), but in cases of food fraud there are always definable victims such as other market actors, traders or buyers, who have been deceived to engage in the purchase of product below market value — if the buyer was aware of the fraud, they would not pay the expected price (see Naylor 2003). While such frauds may often be economically motivated (see Spink and Moyer 2011), such unidimensional explanations can obfuscate the heterogeneity of reasons and influences that shape how and why these frauds take place (Lord et al. 2017a).

Food frauds often involve legitimate food system actors and businesses who as part of their routine activities need to manage supply, demand, competitors and regulators to maintain enterprise. This directs us towards analysing the situational drivers and pressures (contingent conditions), and inherent features and activities of fraudulent behaviours (necessary conditions) that facilitate the 'survival' or profit-seeking of the 'business'. Food frauds can facilitate the maintenance or acquisition of business within the market and we can utilise the enterprise model to view such crimes 'as the product of market forces, similar to those that cause legitimate businesses to flourish or die in the legal sector of the economy' (Albanese 2012: 11). In this sense, enterprise theory posits that all enterprises exist to survive and/or make a

\footnotetext{
${ }^{6}$ The concept of 'enterprise' can also represent an object, such as a particular company or business, but here we are more interested in the behavioural dynamics of enterprise as a set of processes.
} 
profit, and in the case of food fraud as commercial enterprise crime, as we see the provision of 'legal' goods, there is scope for large-scale market control unlike when the enterprise involves 'illegal' goods that subsequently restrict scale and lead to the emergence of smaller, more flexible and efficient enterprises (see Paoli 2002; Albanese 2012). Under these varying conditions, 'drivers' represent those factors that have causal potential and thus may contribute to decisions to engage in frauds. ${ }^{7}$

Understanding food fraud as 'enterprise' re-organises our thinking to better understand situations, contexts and structures that pressure, drive or 'make rational' decisions to engage in fraud. In this sense, we must understand food frauds as 'situated action'. The concept, originally coined by Lucy Suchman (1987), has been notably applied in the cognate criminological area of organisational crime by Vaughan $(1996,1998,2007)$ who states:

'[a] fundamental sociological understanding is that interaction takes place in socially organized settings. Rather than isolating action from its circumstances, the task of scholars is to uncover the relationship between the individual act and the social context' (Vaughan 1998: 31).

We must therefore consider how specific situations, including the material and social circumstances and conditions, shape offending behaviour and how we can subsequently intervene with these facilitative situations. By analysing situated actions, we can integrate theories of situational prevention with our framing of food fraud as enterprise crime.

Situational prevention theory is concerned with understanding the circumstances of crime and in particular the availability of opportunities to commit crime using the principles of routine activity theory. Rather than focusing on the distal causes of crime or inherent criminal motivations and propensities, the theory focuses on practical ways of reducing opportunities for crime or minimising their harms (see Eckblom 2003; Bullock et al. 2010). Various empirical studies have supported the benefits of situational prevention and routine activities (in relation to white-collar crime specifically see Benson and Madensen 2007; Benson et al. 2009; Benson and Simpson 2015). However, one limitation is that the precise strategies needed for crime reduction are not always evident. For instance, the theory indicates that prevention measures ought to be directed towards five specific mechanisms:

1. increase the effort for offenders (e.g. making it harder to adulterate food products or to hide frauds behind legitimate business practices by increased transparency),

2. increase the risks (e.g. increase routine surveillance of the business environment, that is, the 'offending locations' or the likelihood of being detected, such as by buyers and consumers),

3. reduce the rewards (e.g. separate products within the business or confiscate profits gained),

4. reduce provocations (e.g. reduce temptations to commit fraud by ensuring legitimate business is profitable or neutralising organisational/market pressures), and

5. remove excuses (e.g. introducing more prescriptive rules or educating offenders to harms caused).

The particular methods to be used are determined by the specifics of the type of fraud (e.g. adulteration may require different prevention mechanisms to mislabelling) and its

\footnotetext{
${ }^{7}$ A 'driver' could be a 'condition' and a 'condition' could be a 'driver', but a driver has causal potential whereas a condition provides the contexts and situations within which frauds occur.
} 
underlying preparatory behaviours, called 'scripts' (i.e. deconstructing what has to be done and by whom in order to accomplish the fraud) (see Lord et al. 2017b). However, empirical efforts demonstrated that it is not always clear which specific mechanisms will have the desired impact on the targeted criminal behaviour (see for example Kleemans et al. 2010). Integrating situational prevention with enterprise theory enables us to identify which specific mechanisms can have preventive impacts.

\section{The contingent conditions of food fraud enterprise: Supply, demand, regulation and competition}

The conditions that shape food fraud enterprise are contingent upon the geo-histories (see Edwards and Hughes 2005) of the particular locations where they occur. By 'conditions', we mean those circumstances and features of markets and business that shape how the food fraud enterprise is organised and carried out. That is, conditions relating to the nature of supply, demand, regulation and competition (Albanese 2012) as occurring within broader politicaleconomic-social environments vary across contexts and the mix of such conditions can create more, or less, conducive environments and situations for food frauds to take place. Under these conditions, decisions and behavioural/normative preferences emerge, and these are shaped by institutional cultures. As Vaughan (1998: 31) notes,

' $[t]$ he important role of culture in situated interpretation, meaning, and action is reinforced by...the new institutionalism, which explains that organizational forms and behaviors take the form they do because of prevailing value and beliefs that have become institutionalized to varying degrees'.

Thus, in terms of business and food fraud, by looking to understand key aspects of the enterprise model, broken down into its component parts, we can see that food fraud criminality is shaped by the need to account for:

a. supply (of the materials needed to adulterate, such as horsemeat for beef mince, or labelling equipment for re-packaging),

b. the nature and location of demand (by actual and potential customers),

c. the presence and competence of regulators (e.g. Food Standards Agency, Trading Standards, the police), and

d. competitors (comprised of other food businesses who may or may not be engaging in food frauds).

Figure 1 provides a visual representation of these pressures and drivers in the context of food fraud criminal enterprise. The manifest responses to such pressures and drivers are shaped by business and industrial cultures, as individual actors draw upon the norms, values and underlying assumptions that they have learned through processes of socialisation in these contexts.

A failure to manage each of these components can reduce profitability and jeopardise market survival. For each component of the enterprise, specific indicators can be developed to understand situations and environments that shape the nature of supply including market volatilities and opportunities, intersecting product markets, and contractual arrangements. Demand includes the level of demand and potential for growth, and whether it is elastic or 


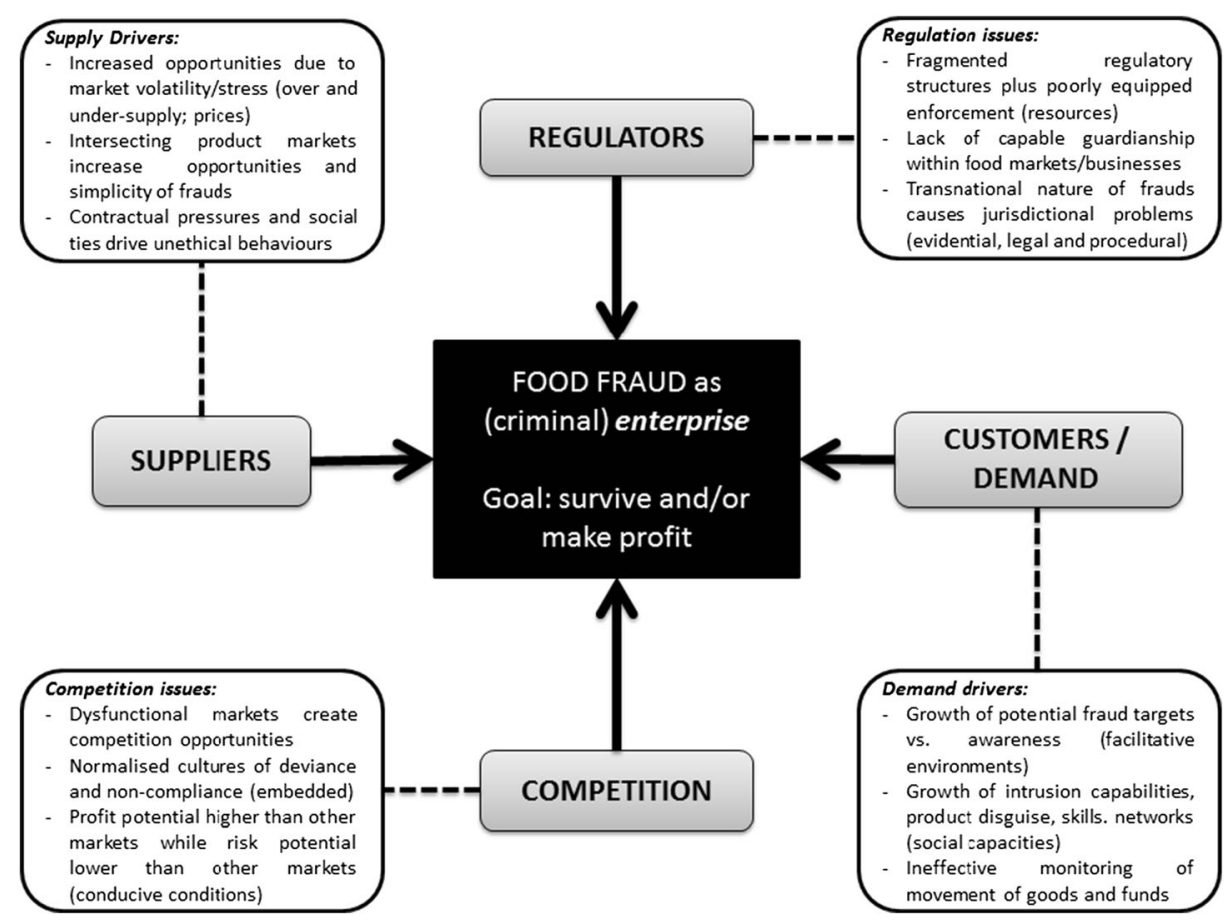

Fig. 1 An enterprise model of food fraud operation in licit markets (adapted from Albanese 2012)

inelastic, and abilities to move concealed illicit products. Competition from other groups and products; dysfunctional food markets create overlapping opportunities for commerce and increased amenability for seeking profit while minimising risk) and regulators, where there is regulatory fragmentation and complexity, the ease of entry into the licit market or product, based on existing regulations and any special skills needed, and the capacity and effectiveness of law enforcement in that market. We therefore need to organise our thinking to understand these situations, components and their influence on individual and collaborative behaviours. Below, we apply this model to the enterprise of olive oil adulteration.

\section{The necessary conditions of food fraud enterprise: The organisation of olive oil adulteration}

Food fraud enterprise can incorporate a diverse array of behaviours. By understanding the necessary conditions of particular food frauds (i.e. the essential mechanics of the fraud, in other words, what must happen), we better understand the dynamics and interactions of individual and/or collaborative behaviours within the conditions and drivers (supply, demand, regulation, competition) under which they occur. The previous definition of food fraud (Lord et al. 2017a) assists us to understand food fraud where decision-making cannot be separated from social context, and recognising this reinforces the limits of reducing all food fraud down to being 'economically motivated' (see Spink and Moyer 2011).

Motivations can be heterogeneous, as some food frauds may not be pre-planned but may be located on a 'slippery-slope' of actions such as when market pressures and structures combine 
to create conditions under which businesses are left with large surpluses and a saturated market (Lord et al. 2017a). Whether the food fraud is pre-planned or not, is a one-off incident, a series of incidents, or is embedded and routine practice, the fraudulent behaviours are influenced by the enterprise components and irrespective of the scale of the enterprise. Food frauds require behaviours and social relations that need organising around commercial opportunities that emerge within particular market and organisational conditions and forces. Those who exploit such opportunities must manage the 'enterprise' to maintain a successful business (see Albanese 2012). We focus on this by drawing on three cases of olive oil fraud in Spain involving the adulteration of the products to better understand the necessary aspects of such frauds.

\section{Olive oil fraud in Spain: Operación Lucerna, Operación Cloroil and Operación Colesterol}

As part of our research, we documented three fraud cases in Spain. These cases constitute complex webs through which the offenders sold adulterated olive oil. We outline details of these cases below in order to illuminate the dynamics of such olive oil adulteration.

\section{Case 1 - Operación Lucerna}

Operación Lucerna exemplifies a complex structure for the adulteration of olive oil in which issues of integrity conflate, i.e. product integrity, process integrity, people integrity and data integrity, all of which are central to the fraud. Operación Lucerna began at the end of 2010 when Agengcia Tributaria (Spanish Tax Authority) detected that companies associated with Enrique Fuentes Ibáñez had imported large amounts of avocado and palm oil from Ecuador. The imported oils were used to adulterate extra virgin olive oil (people integrity) and the adulterated oil was sold in Spain and Italy (product integrity). The adulterated extra virgin olive oil was produced at a biodiesel factory in Mengibar (Jaén). This production facility was not an approved premise for the production of food for human consumption (process integrity). The production of the adulterated oil was a complex process; the oil was highly refined to the extent that traces of avocado or palm oil were not identifiable in the final product. The product was sold cheaply, allowing the producers a market advantage and it gave rise to unfair competition in the market. The authorities identified two methods to place the 'olive' oil in the market: 1) selling the oil in bulk to third companies unaware of the fraud (most of the oil was sold in bulk); and, 2) the bottling and labelling of the blend marketed as olive oil by a bottler in Pegalajar (Jaén).

The case involved a complex international web of more than 30 companies in Spain, Italy and Portugal, which used false documents to place the adulterated 'olive' oil into the market through shell companies in the food production sector (data integrity). ${ }^{8}$ It can be argued that there was clear evidence of adulteration, however, the prosecution charged the offenders for defrauding the Public Treasury on VAT rather than the more complex criminal charges of fraud. The prosecutor argued that the irregular activity did not constitute a crime because some of the oil collected by the authorities did not coincide with the labels on the bottles. Additionally, the misrepresentation did not materialise because the adulterated oil was seized at the production plant and had not entered the retail market. Furthermore, the authorship of the crime was blurred and there was no known harm to public health. Finally, the prosecution

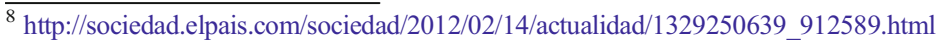


argued that the consumers had not raised any claim before the authorities and the alleged illegal act could not be prosecuted without a claim because the public interest was not affected. ${ }^{9}$ In November 2015, Enrique Fuentes Ibáñez was convicted to four years in prison and a fine of $€ 1,000,000$ for the VAT and associated offences. The Spanish Supreme Tribunal confirmed the conviction; however, the penalty was reduced to three years and three months in September $2016 .^{10}$

\section{Case 2 - Operación Cloroil}

In this second case Enrique Fuentes Ibáñez, with previous convictions for fraud, was again involved. He was charged with nine co-defendants with offences including forgery, harm to public health and belonging to a criminal organisation. These offences were all concerned with the sale of adulterated 'olive' oil (people integrity). In the Operación Cloroil, the authorities seized 120 t of adulterated 'olive' oil (product integrity). The modus operandi was similar to the Operación Lucerna case. A biodiesel company in Mengíbar imported sunflower oil from France, avocado oil from Greece and palm oil from Ecuador. The company also imported food additives and colourants, these are not required in the production of biodiesel and so were not a legitimate part of their business activity. In this case a slightly different approach was used, the adulterated oil was not produced at the biodiesel factory but was blended by using a number of different blenders (process integrity). The fraud required forged shipment notices and the falsification of information regarding entry, exit, origin and destination in order to hide the fraudulent activity (data integrity). It was the representative groups of olive farmers and cooperatives that raised their suspicions with the authorities that resulted in the investigation. Except for Enrique Fuentes Ibáñez and his son, the name of the companies involved and their owners and managers has not been released. This is worth noting considering that in the previous case example, Operación Lucerna, a diversity of associations requested the authorities to name and shame those companies involved in order to protect the reputation of the olive oil region, however, this request was denied.

\section{Case 3 Operación Colesterol}

Operación Colesterol was initiated by people in the olive oil industry. These claims were substantiated by the detection of adulterated olive oil in random official tests. In the investigation, 76,000 1 of sunflower oil were disguised as olive oil by using preservatives and colourants. The fraud occurred from 2005 to 06 , a period in which there was a severe increase $(43.8 \%)$ in the price of olive oil to around $€ 5$ per litre. Two companies in Mancha Real (Jaén) and Baena (Córdoba) were involved in the fraud. In these companies the oil was produced, bottled and labelled as 14 different brands such as Embrujo de Andalucía, Los Olivares, La Bodega, La Colmena, La Cantanilla, Conde Da Vila, Aceite del Serra and la Despensa. These bottles of oil were sent to distributors in Cataluña, which in turn commercialised the oil in tourist coach trips where the oil was sold to tourists and elderly people, in addition to selling the oil to wholesalers, small stores, restaurants and through Internet websites. In most cases, the olive oil content did not exceed $20 \%$ of the final product.

\footnotetext{
${ }^{9}$ http://www.diariojaen.es/historico/operacion-lucerna-el-fiscal-no-ve-delito-en-la-mezcla-de-aceitesAXDJ12741

${ }^{10} \mathrm{http} / /$ www.diariojaen.es/jaen/el-supremo-rebaja-la-condena-a-enrique-fuentes-por-fraude-LF2160269
} 
The authorities seized not only the oil but also the associated equipment and materials including bottles, cans and labels for 14 different brands. There was a scheme in place to finance the necessary elements required for the commission of the fraud. In an industrial unit in Mancha Real, which was used for the adulteration, the authorities found 18,600 1 of oil, 1280 empty cans ready for bottling, 4000 five-litre containers and 1000 labels from diverse brands. In a second location (Baena, Córdoba), the authorities seized 20,800 1 of sunflower oil, 16,7101 of extra virgin olive oil in five-litre containers, 3000 new plastic bottles and 14,000 cases for bottling. The investigation led to multiple arrests, for which two people were convicted to two years in prison for fraud.

\section{Applying the integrated framework: Understanding the necessary and contingent conditions of adulteration in the Spanish olive oil market}

A focus on the nature of the fraudulent activities within particular markets, rather than only on who the 'criminals' are, provides a more coherent, comprehensive approach to intervening with food frauds. Within this framework we can identify and evaluate conditions that are conducive to fraud based on accumulated knowledge of markets, products and activities. The first step is to assess supply drivers, demand drivers, regulation issues and competition issues within different product markets or regions. This assessment must occur prior to taking action, because without systematic information we cannot be sure that the (most serious) vulnerabilities within a market or sector are being targeted. Consequently, rigorous identification and updating of these drivers by improved and continuous collection of data on incidents will result in the accurate targeting of activities that pose the highest risk. We demonstrate this approach here with an analysis of adulteration and fraud in the Spanish olive oil market.

\section{The olive oil production process and associated dynamics}

Our research commenced by developing a flow chart of olive oil production, informed by interviews with industry actors, to enable an understanding of the organisation of the network of actors and processes necessary to lawful production. Figure 2 provides visualisation of the structure and organisation of the production process.

We also obtained aggregate data relating to production, consumption, imports, exports (Table 1) in addition to market share (Table 2 ) and data on price volatility. Table 3 extrapolates the contingent enterprise drivers and conditions from the Spanish context.

\section{Spanish olive market in the twentyfirst century}

The structure of the Spanish olive oil industry is complex. According to the Ministry of Agriculture, Food and Environment, five bottlers hold 35\% of the bottling of olive oil, and for the first 15 bottling companies the market share increases to $58 \% .{ }^{11}$ In the refining industry, there are eight refineries, two of which refine $70 \%$ of the pomace oil. ${ }^{12}$ In 2015 , five

\footnotetext{
${ }^{11} \mathrm{http} / /$ www.magrama.gob.es/es/alimentacion/servicios/observatorio-de-precios-de-los-alimentos/ESTUDIO PATATA_14112010_tcm7-182793.pdf

$12 \mathrm{http}: / / \mathrm{www} . \mathrm{mag}$ rama.gob.es/es/alimentacion/servicios/observatorio-de-precios-de-losalimentos/estudiodefinitivoaceiteorujo2011-12reducido_tcm7-382062.pdf
} 


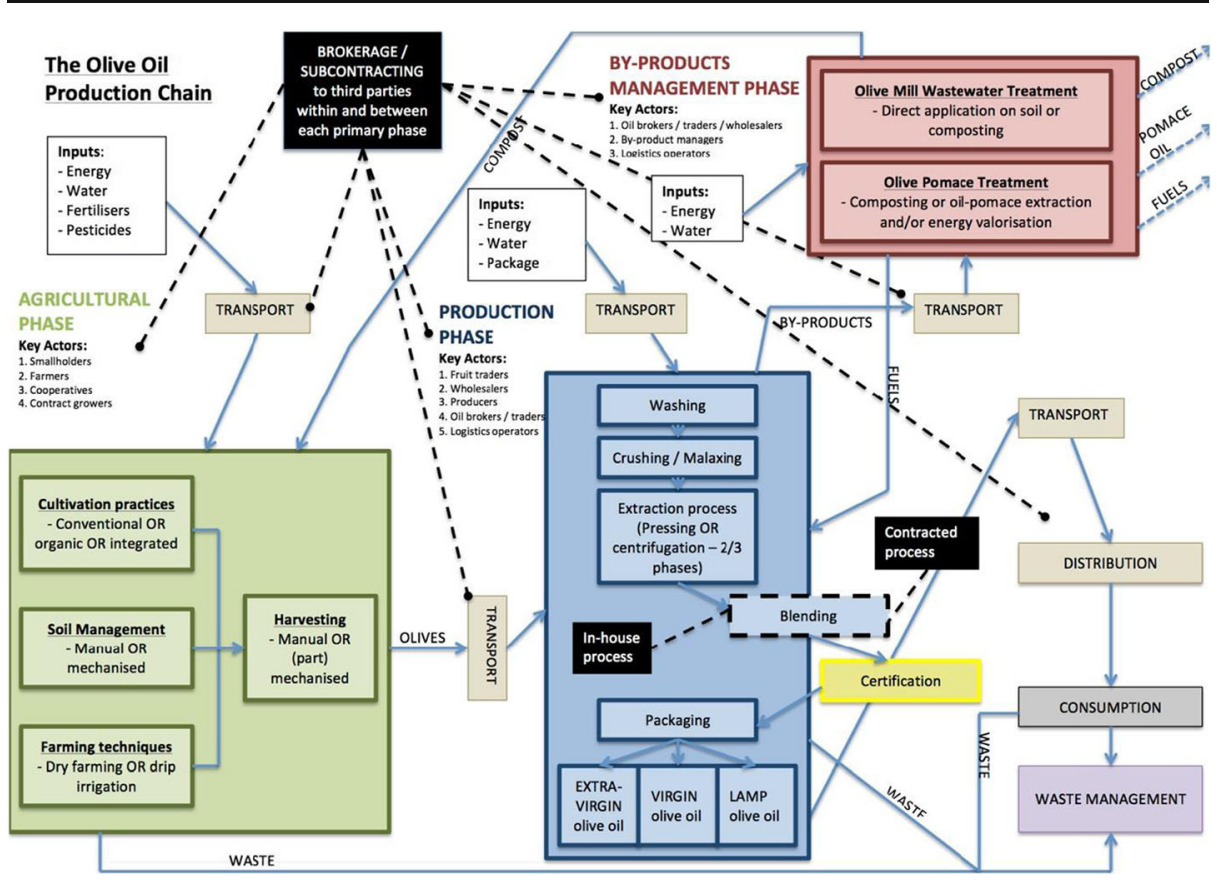

Fig. 2 The olive oil production chain (adapted from EMAF http://ww2.unime.it/emaf/index.php?option=com content \&view=article $\&$ id=54\&Itemid=42\&lang=en)

Table 1 Production, Consumption, Imports and Exports of Olive Oil in Spain

\begin{tabular}{lclrr}
\hline Year & Production (thousands of tonnes) & Consumption & Imports & Exports \\
\hline $2009 / 10$ & 1401.5 & 533.4 & 47.0 & 780.1 \\
$2010 / 11$ & 1391.9 & 554.1 & 43.5 & 827.9 \\
$2011 / 12$ & 1615 & 580.9 & 59.8 & 875.5 \\
$2012 / 13$ & 618.2 & 499.2 & 119.2 & 630 \\
$2013 / 14$ & 1781.5 & 536.5 & 57.6 & 1102.9 \\
$2014 / 15$ & 842.2 & 494.6 & 159.1 & 826.4 \\
\hline
\end{tabular}

Source: Ministry of Agriculture, Food and Environment, Cycles 2013/2014, 2014/2015 and 2015/2016 (Statista 2017)

companies accounted for $40 \%$ of the market share of olive oil (Euromonitor International 2016). Supermarkets account for $45 \%$ of the retail market share (Statista 2017). Distributor's brands hold the highest share of the market accounting for $68 \%$ of the olive oil market. ${ }^{13}$ So, maintaining and expanding market share is complex. The oil mills place their oil into the market by using brokerage houses. In Spain, much of the oil is sold on the market in bulk, only $25 \%$ of the export market is sold as bottled (Cohard and Rosa 2012). Bottlers without their own refineries buy virgin oils from mills and refined oils from third parties through brokers. In bottling facilities, the virgin olive oil is bottled for consumption and/or blended to produce olive oil through the mixture of virgin and refined oils.

\footnotetext{
$\overline{13}$ http://www.agrodiario.com/texto-diario/mostrar/492044/agricultura-habilita-ano-190-millones-euros-ayudassector-olivar
} 
Table 2 Market share of olive oil sales in Spain

Market share (\%) in 2014

\begin{tabular}{llll}
\hline Supermarket & Hypermarket & Discount shops & Traditional grocery \\
\hline 48.7 & 24.8 & 14.7 & 1.4 \\
\hline
\end{tabular}

Source: Ministry of Agriculture, Food and Environment (Statista 2017)

The Spanish market is characterised by the concentration of the market with a handful of 'players' and by two very entrenched vertical relationships. The distributors have gained considerable negotiating power due to recent structural changes. This marks out along with the consolidation of cooperatives both of first and second degree, the Spanish market as being different to other markets where cartel-like private organisations appear to act with the support of the government to control the price of olive oil.

After the financial crisis in 2007 there were three significant changes to the production and supply arrangements of olive oil in Spain (Navarro 2010). The growth of second degree cooperatives, changes to the distribution strategies of large cooperatives and the increase in retailer 'own brands'. DCOOP (previously Grupo Hojiblanca) is a second-degree cooperative comprising 110 associated cooperatives. It is the world leader in olive oil production averaging production of $220,000 \mathrm{t}$ per harvesting cycle. Second degree cooperatives aim to counteract the power of distributors and these cooperatives have increased the amount of bottled olive oil that is sold. This demonstrates their ability to exercise some control over the market. The changes to distribution have also been significant. The Compañía Española de Comercialización del Aceite, for example, comprises around 250 cooperatives accounting for $60 \%$ of olive oil production. They are able to control market price by deciding on the amount of oil to be released onto the market from their stores of oil, which is around $20 \%$ of total production in any one year. Such 'arrangements' appeared to contravene competition rules but they were approved by the Spanish Supreme Tribunal on appeal after the Competition Tribunal had declared it illegal. The increase in retailers' own brands concentrated demand. One consequence of this was a 'price war' due to the pressures on prices that reduced supply chain profit margins. Olive oil is used by many retailers as a leading product and on occasions supermarkets will use olive oil as a 'loss leader', prepared to sell their own brands at a loss. ${ }^{14}$ The increase in own brands has seen the demand for olive oil increase and the big cooperatives, to exert some control over the market, have entered the bottling and refining sector (Navarro 2010) to try and retain a power symmetry between producers and retailers. Finally, the recent concentration of milling cooperatives has resulted in a concentration of supply, which has led to the bottling of olive oil becoming more expensive (Ibid). A relatively cursory glance at the Spanish olive oil market confirms the role cooperatives have not only in price negotiations but also in controlling the market through several mechanisms, particularly the co-ordination of supply.

The post-financial crisis olive oil market was characterised by price volatility both at origin and at consumption (Navarro 2010). This volatility impacted both the internal and export markets. One consequence is the diversification of supplies, for which bottlers and refineries established companies in third countries on the Mediterranean coast. In 2010, some of the large companies that had established premises in third countries in the Mediterranean; for example

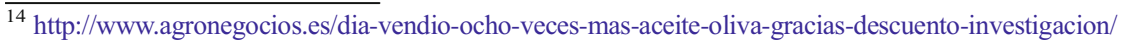


Table 3 Contingent enterprise drivers and conditions

Production (e.g. millers undertaking washing, crushing, extracting, refining, bottling, transport)

Supply

Drivers:

- Concentration of supply by which the bottling of olive oil has become more expensive.

- Production exceeds consumption creating a state of perpetual oversupply for domestic markets.

- Mills must operate at 'optimum capacity' to be viable which creates surplus.

Conditions:

- Cooperatives remain weak in negotiations.

- Bottlers buy virgin oils from mills and refined oils from third parties - if they do not have their own refineries.

- Source oils bottled and in bulk from multiple suppliers, often via brokers and traders.

- Key distributors and wholesalers have close personal and business connections.

- Brokers play significant roles for mills. They ensure that networks are innovative, creative and integrated.

- Brokers are critical in maintaining the functioning of the market for wholesalers and manufacturers in obtaining product and disposing of 'production errors'; provide a service to markets in maintaining supply and ensuring a flow of product; provide access to external sources from the supply chain and at a number of different locations within intersecting markets.

Demand Drivers:

- Price volatilities when buying in supply. This leads to confrontation between the traditional industry (bottling and refining) and producers (growers and mills). The power shift to distributor's own brands has confronted industry (bottling and refining) to distributors at the consumer-end.

Conditions:

- Steady consumer demand in context of market volatility.

- Intersecting markets increase perceived simplicity of fraud.

- Ready-made, fluid transactional networks already in place

- Price volatilities at consumer end.

Regulation Drivers:

- Lack of credible regulatory oversight and capable guardianship (a necessary but not sufficient condition).

- Normalised cultures make prohibited conduct acceptable.

Conditions:

- Domestic price volatilities lead to diversification of business models to foreign markets.

- Increase in the investments of foreign commercial groups.

- The production and reproduction of structural dysfunctionality.

- Traceability of product becomes difficult.

- Structure of the market and the different levels of activity, e.g. use of (online/offline) brokers and economics of the trade.

- Legal and enforcement fragmentation in the diverse autonomous regions.

- Regulatory decision to allow the importation of duty-free olive oil from Tunisia after the terror attacks in 2015 (35,000 t per year until 2017).

Competition Drivers:

- Product is stored by dominant cooperatives (essentially cartels under EU law) and released as prices climb to maximise profit which creates pressures for competitors.

- Increase in own brand products, which have led to the concentration of demand, pressures on prices and a reduction on the margins of the whole supply chain due to war prices. Retailers are selling olive oil at a loss to attract clients.

- Taking a loss has significant financial impact (false profits/losses) - criminal necessity as a consequence of market practices in order to maintain cash flow.

Conditions:

- High concentration of ownership: five bottlers hold $35 \%$ of the share of the market and the first 15 bottlers hold $58 \%$ of the market; four export companies hold $60 \%$ of the share of exports.

- Power rests with main distribution groups who negotiate with their suppliers, who are not the producers/mills organised in cooperatives but bottling companies.

- Strategic problem of commercialisation with a division between producers, mills and bottlers, and distributors.

- Distributors of own brands hold the highest share of the market accounting for $68 \%$ of the olive oil market and $45 \%$ of extra virgin olive oil.

- Futures market of olive oil operated until November 2014, adding to the volatility of the market. 
Borges, Acesur, Ideal and SoS (now Deoleo). There is also investment activity by the Spanish commercial companies in third countries, either through the acquisition of distributors or purchasing equity in such companies.

\section{Necessary and contingent conditions for fraud in the olive oil market: An integrated application of enterprise and situational theory}

The focus in this paper is on adulteration rather than forms of falsification such as mislabelling or mis-description, or forms of tax and subsidies frauds, although there is often overlap between these fraud types. Adulteration results in varying integrity issues: product integrity (i.e. the inherent quality of the oil is not as expected), process integrity (i.e. insufficient quality assurance or incapable monitoring), people integrity (i.e. those involved have intentionally, and immorally, engaged in deception) and data integrity (i.e. accompanying product information is inaccurate) (see Manning 2016). By applying the enterprise model and understanding the wider enterprise conditions discussed above, and integrating this with situational prevention theory, we can begin to identify and understand how businesses in the olive oil market survive and make a profit by addressing supply, demand, regulation and competition pressures in their own environments during the production of olive oils. These enterprise conditions are contingent and vary by context.

The conditions outlined above shape the nature and organisation of the olive oil frauds and we can begin to deconstruct the necessary processes inherent in olive oil adulteration as seen in the cases above. In other words, what should be done, who does what and which conditions facilitate the commission of the adulteration? In this sense, we can distinguish between the necessary and contingent conditions of olive oil adulteration. Involved actors must, for instance, source alternative oils and manufacture the fraudulent oil blends. They must conceal these behaviours within their other legitimate business environments and practices and then integrate the fraudulent product into the market. This requires using third-party logistics companies, they are likely to be unwitting but may collude, during distribution to retailers and consumers. Furthermore, the finances used to procure the ingredients and/or equipment needed for adulteration may need to be accounted for while the 'criminal proceeds' obtained through the fraud need managing. These processes necessitate the involvement of witting and unwitting actors, and those who wilfully turn a blind eye to potential fraud. Colluding actors must be a reliable and 'trusted' network of cooperating actors, otherwise the enterprise is vulnerable to detection. These actors must also possess an understanding of manufacturing/ production, logistical arrangements, structures and 'ideal' routes, as well as knowledge of (cross) jurisdictional enforcement conditions and likely areas of routine detection, capable guardianship and regulatory/compliance gaps. Thus, the involved actors have legitimate access to offending locations, they appear as legitimate business actors and utilise legitimate business practices to conceal fraud, they exploit 'ready-made' market structures and transactions and they have spatial separation from victims.

\section{Situational prevention mechanisms for olive oil adulteration in production}

Following this approach, the enterprise perspective can be used to categorise the multiple drivers and conditions influencing a range of behaviours in the olive oil industry. Once we 
understand these necessary and contingent conditions, we can then integrate the principles of situational prevention and outline actual and potential situational mechanisms for reducing and preventing food fraud in the olive oil production chain. We can identify mechanisms for re-shaping the situated choices of individual actors by influencing how they interpret and interact with these wider structural pressures through their organisational business cultures.

In the case of olive oil adulteration in the Spanish market, we see that higher quality products have been stretched, diluted or 'cut' with lower quality olive oils (e.g. mixing refined olive oil with extra virgin olive oil) or incorrect oils (e.g. avocado or palm oil). Such fraudulent behaviours occur within legitimate business settings where we see the abuse or misuse of otherwise normal, routine practices by occupational actors during the production phase. Such dishonest acts seek to gain some form of business gain but involve deception of buyers, producers or consumers at some subsequent stage. While such adulteration may contravene legally prescribed procedures and rules, in some cases such behaviours may be normatively and culturally accepted within the industry as market pressures lead to innovation and creativity in business (Lord et al. 2017a).

With reference to Fig. 2, large-scale adulteration is unlikely to occur during the agricultural phase (i.e. growing, cultivation and harvesting). First, there is insufficient volume for notable profit. Second, there is insufficient equipment and expertise for large-scale adulteration. Third, there is a preponderance of 'vocational' rather than 'entrepreneurial' actors in the agricultural phase whose primary pursuit is for the 'way of life', rather than as entrepreneurs. Instead, adulteration and illegal blending are more likely to occur at the production stage. More specifically, adulteration is likely to occur between post-extraction and pre-packaging (i.e. blending and refining) as the effort required to adulterate once packaging and bottling has taken place is too great. At the processing stage, we see the potential for lower quality oils (e.g. lamp oil, virgin oil) to be illegally blended with higher quality oils (e.g. extra-virgin). Supply chains, a legitimate structure and network, provide a 'ready-made' network for organising criminal behaviours and moving illicit products. Understanding these necessary and contingent conditions of olive oil adulteration permits the development of situational interventions and key points of vulnerability. Figure 3 sets out some example mechanisms for situational prevention.

By integrating an understanding of the enterprise conditions that shape how and why olive oil adulteration is organised as it is and the associated pressures and drivers, we can then analyse the situations where the frauds take place with a view to preventing them. These interventions can be organised around the five specific mechanisms of situational crime prevention. For instance, regulators, such as law enforcement authorities or industry regulators, could aim at increasing the effort required to adulterate olive oil by introducing requirements around the transparency of transaction data, that is, the data on types and quantities of products sourced, from where and for what purpose. Public or state auditing of such data would give insights into anomalies in the business model, for example the adulteration of olive oil with hazelnut oil.

Increasing the risks associated with adulteration also provides scope for prevention. For instance, increasing the level of non-routine inspection measures in key locations, such as mills and refineries, introduces more capable guardianship and acts as a deterrent. Mechanisms could also be introduced to incentivise external whistleblowing by business employees or 'bell-ringing' by third parties. This addresses a key difficulty for regulators as gaining knowledge about fraudulent practice in what are often 'closed' markets is a major obstacle to regulation. Furthermore, requiring businesses to undertake more stringent due diligence on partners, suppliers and purchasers would increase the self-regulatory capacities of the business community. For instance, if an olive oil refinery is sourcing chlorophyll or colourants, which 


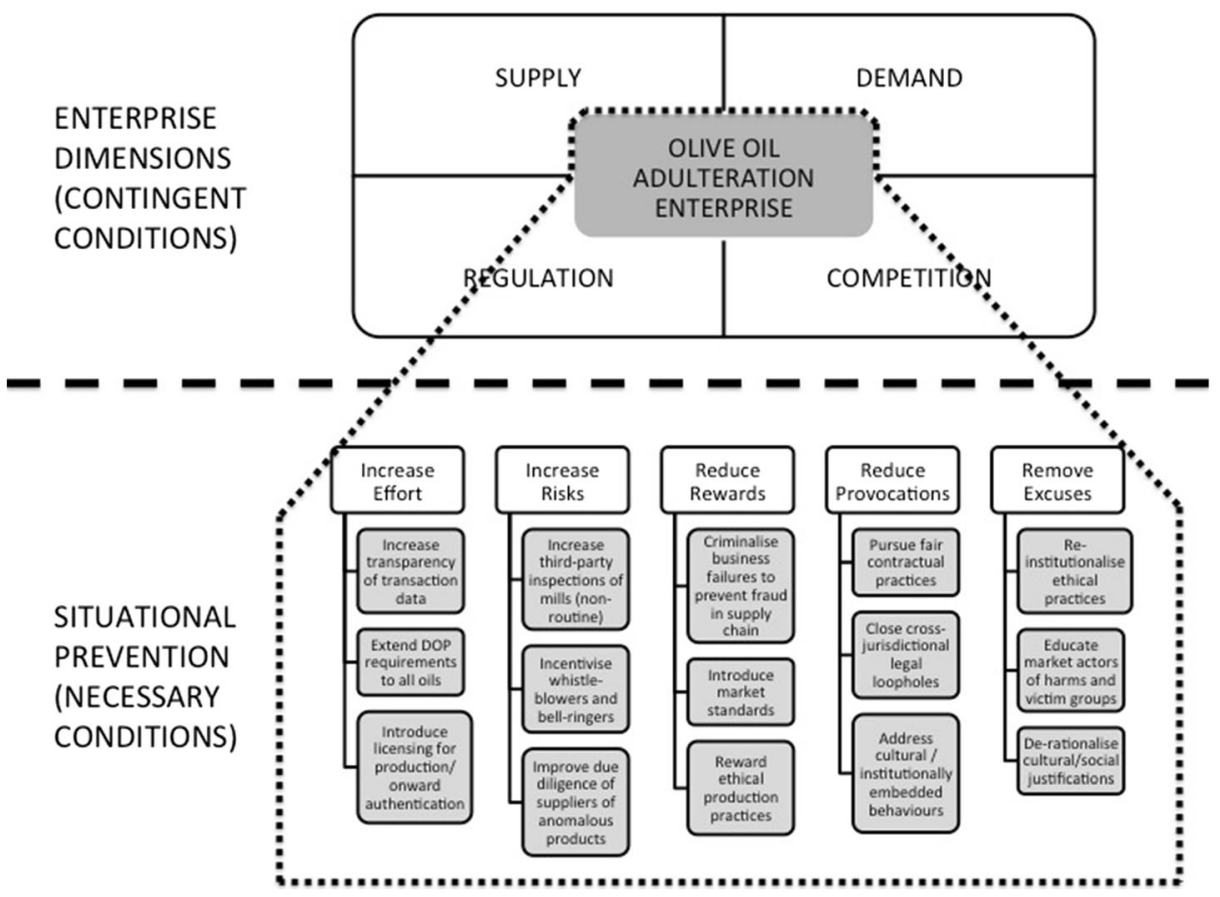

Fig. 3 The integrated framework

can be used to alter the appearance of adulterated oils, then this ought to raise a 'red flag' for the supplier who can notify the authorities.

The rewards generated from food fraud can also be reduced to disincentivise those actors who may benefit from adulteration. For instance, as in the Spanish cases, well-known businesses were at the centre of the allegations and financially benefited from buying or producing oils at cheaper cost through their associates. In such scenarios, the criminalisation of the failure of corporations to prevent fraud throughout their organisational structure and business relations places the onus on these companies to ensure sufficient systems and controls are in place to prevent fraud from occurring. Similarly to recent developments with the UK Bribery Act 2010 and the Modern Slavery Act 2015, where businesses become vicariously responsible for the actions of their associates. Such criminalisation could coincide with the development of industry standards, norms and values across the market with independent bodies evaluating, scrutinising and/or certifying the presence of increased standards within the market. 'Good' ethical production practices could then be rewarded including tax benefits and access to vulnerable markets such as tourist markets.

A key issue in food frauds is that such behaviours appear to become normalised across food sectors and markets (see Lord et al. 2017a). This cultural and institutionalised embedded behaviour perpetuates unethical practice and creates provocations for businesses that may be disadvantaged through such practices and thus enter a 'slippery slope' of non-compliant behaviours. This is further exacerbated by the corporatisation of the food system and the proliferation of imbalanced contractual practices as 'big business' is able to benefit from positions of power. State intervention to ensure fair contractual practices can remove some such provocations and enable businesses to compete in a fairer playing field. Corporations are also 
able to benefit from the creation of complex ownership structures, often organised transnationally, to dominate the market and institutionalise the aggressive pursuit of profit by rewarding quick business gains as their companies compete against each other for such rewards. Thus, by re-institutionalising the rewarding of ethical practice rather than aggressive risk-taking within the food markets the excuses for adulteration can be removed. This must coincide with increased education of market actors about the harms and victims of olive oil adulteration. Doing so can ensure adulteration and frauds become more difficult to justify and rationalise.

\section{Concluding thoughts}

This article has presented a conceptual and analytical framework for preventing food fraud informed by a situational understanding of the nature of the activities and behaviours involved in the fraud. By integrating models of enterprise with models of situated action, we can gain a fuller theoretical account of food frauds and how we can prevent them. Here we can distinguish between the contingent conditions that shape the environments and situations conducive to food frauds and the necessary conditions of the fraud commission process. Preventive, proactive thinking and analysis is the logical progression of state and non-state responses to food fraud (see Spink and Moyer 2011) and provides a framework for linking together the varying agendas of state authorities concerned with overlapping but distinct policy concerns.

It has been our contention that by framing food fraud as a commercial enterprise crime and using this conceptual framing to inform situational prevention strategies, integrity in the food system can be pursued and enhanced through prevention. We demonstrated how by integrating these theoretical perspectives, adulteration within the olive oil markets at the stage of production could be prevented and reduced. If we can redefine the responses, actions and preferences of market actors to external pressures and drivers around ethical practice, this can in turn reduce choices to engage in fraudulent behaviours. We suggest that this mode of thinking and analysis can be transposed to other phases of the olive oil market but also to other products and markets. This in turn facilitates comparative analysis that can inform the identification of common and different areas of points of vulnerability and thus inform where resources ought to be directed in the prevention of food fraud. While we focus here on intervening with the situated actions and environments of fraud, this approach should also be informed by empirical research into the generative causes of fraud in the food system. What is more, focusing on specific locations can result in insufficient attention being placed on the system. Consequently, while situations can be altered to prevent fraud, we must also be critical of the ways in which markets and industries may be dysfunctional as they produce and reproduce conditions facilitative of fraud.

Acknowledgements This work was supported by the Economic and Social Research Council (ESRC) and the Food Standards Agency (FSA) in the UK (Grant Number ES/M003183/1).

\section{Compliance with ethical standards}

Conflict of interest The authors declare that they have no conflict of interest.

Open Access This article is distributed under the terms of the Creative Commons Attribution 4.0 International License (http://creativecommons.org/licenses/by/4.0/), which permits unrestricted use, distribution, and reproduction in any medium, provided you give appropriate credit to the original author(s) and the source, provide a link to the Creative Commons license, and indicate if changes were made. 


\section{References}

Albanese, J. (1995). White collar crime in America. Englewood Cliffs: Prentice Hall.

Albanese, J. (2012). Deciphering the linkages between organized crime and transnational crime. Journal of International Affairs, 66(1), 1-18.

Beckert, J., \& Wehinger, F. (2013). In the shadow: Illegal markets and economic sociology. Socio-Economic Review, 11, 5-30.

Benson, M., \& Madensen, T. D. (2007). Situational crime prevention and white-collar crime. In H. N. Pontell \& G. Geis (Eds.), International handbook of white-collar and corporate crime (pp. 609-626). New York: Springer.

Benson, M., \& Simpson, S. (2015). Understanding white-collar crime. London: Routledge.

Benson, M., Madensen, T. D., \& Eck, J. E. (2009). White-collar crime from an opportunity perspective. In S. Simpson \& D. Weisburd (Eds.), The criminology of white-collar crime (pp. 175-194). New York: Springer.

Bouzembrak, Y., \& Marvin, H. J. P. (2016). Prediction of food fraud type using data from rapid alert system for food and feed (RASFF) and Bayesian network modelling. Food Control, 61, 180-187.

Bullock, K., Clarke, R. V., \& Tilley, N. (2010). Introduction. In K. Bullock, R. V. Clarke, \& N. Tilley (Eds.), Situational prevention of organised crimes. Devon: Willan Publishing.

Cohard, J. C. R., \& Rosa, M. P. (2012). 'Los Canales de Comercialización de los Aceites de Oliva Españoles', Cuadernos de Estudios Agroalimentarios, November 2012.

Eckblom, P. (2003). Organised crime and the conjunction of criminal opportunity framework. In A. Edwards \& P. Gill (Eds.), Transnational organised crime: Perspectives on global security (pp. 242-263). Abingdon: Routledge.

Edwards, A., \& Hughes, G. (2005). Comparing the governance of safety in Europe. A geo-historical approach. Theoretical Criminology, 9(3), 345-363.

Elliot, C./HM Government (2014). Elliott review into the integrity and assurance of food supply networks-final report: A national food crime prevention framework. https://www.gov.uk/government/publications/elliottreview-into-the-integrityand-assurance-of-food-supply-networks-final-report.

Euromonitor International. (2016). Company shares (Global-Historical Owner), Health and wellness: Euromonitor from trade sources/national statistics, available at: www.portal.euromonitor.com.

European Parliament (2013). Draft report on the food crisis, fraud in the food chain and the control thereof (2013/2091(INI), Committee on the environment, public health and food safety. http://www.europarl.europa. eu/sides/getDoc.do?pubRef=-//EP//TEXT+REPORT+A7-2013-0434+0+DOC+XML+V0//EN.

Kleemans, E. R., Soudijn, M. R. J., \& Weenink, A. W. (2010). Situational crime prevention and crossborder crime. In K. Bullock, R. V. Clarke, \& N. Tilley (Eds.), Situational prevention of organised crimes (pp. 17-34). Devon: Willan Publishing.

Levi, M. (2012). Trends and costs of fraud. In A. Doig (Ed.), Fraud: The counter fraud Practitioner's handbook. Gower: Farnham.

Lord, N., Flores Elizondo, C. and Spencer, J. (2017a). The dynamics of food fraud: The interactions between criminal opportunity and market (dys)functionality in legitimate business. Criminology and Criminal Justice. https://doi.org/10.1177/1748895816684539

Lord, N., Spencer, J., Bellotti, E. and Benson, K. (2017b). A Script Analysis of the Distribution of Counterfeit Alcohol Across Two European Jurisdictions. Trends in Organised Crime. https://doi.org/10.1007/s12117017-9305-8

Manning, L. (2016). Food fraud: Policy and food chain. Current Opinion in Food Science, 10, 16-21.

National Food Crime Unit. (2016). Food crime annual strategic assessment. Scotland: Food Standards Agency/ Food Standards.

Navarro, L. (2010). La Estrategía Empresarial en el sector del Aceite de Olivo y su Evolución desde la Transición Política. Revista de Estudios Empresariales, Segunda época, 1, 7-31.

Naylor, R. T. (2003). Towards a general theory of profit-driven crimes. British Journal of Criminology, 43, 81-101.

Paoli, L. (2002). The paradoxes of organized crime. Crime, Law and Social Change, 37, 51-97.

Shears, P. (2010). Food fraud - A current issue but an old problem. British Food Journal, 112(2), 198-213.

Smith Jr., D. C. (1980). Paragons, pariahs and pirates: A spectrum-based theory of enterprise. Crime and Delinquency, 26(3), 358-386.

Spink, J., \& Moyer, D. C. (2011). Defining the public health threat of food fraud. Journal of Food Science, 76(9), R157-R163.

Statista. (2017). Breakdown of Olive Oil Sales Volume in Spain in 2015, by distribution channel. Source: Ministry of Agriculture, Food and Environment. Available at: https://www.statista.com/statistics/444128/olive-oilsales-volume-in-spain-by-distribution-channel/.

Suchman, L. (1987). Plans and situated actions: The problem of human-machine communication. New York: Cambridge University Press.

Vaughan, D. (1996). The challenger launch decision: Risky technology, culture and deviance at NASA. Chicago: University of Chicago Press. 
Vaughan, D. (1998). Rational choice, situated action, and the social control of organizations. Law \& Society Review, 32(1), 23-61.

Vaughan, D. (2007). Beyond macro- and micro-levels of analysis, organizations, and the cultural fix. In H. Pontell \& G. Geis (Eds.), International handbook of white-collar and corporate crime (pp. 3-24). New York: Springer. 